\title{
Structural Characteristics of Moho Surface Based on Time Series Function of Natural Earthquakes
}

\author{
Xuelei Li ${ }^{1,2,3,4}$, Zhuo Jia ${ }^{5,6, *(1)}$, Nanqiao Du ${ }^{3,4}$, Yi Xu ${ }^{3,4}$ and Gongbo Zhang ${ }^{5,6,7}$ \\ 1 School of Mathematics and Statistics, Hunan University of Technology and Business, \\ Changsha 410205, China; lixuelei@hutb.edu.cn \\ 2 Key Laboratory of Hunan Province for Statistical Learning and Intelligent Computation, \\ Hunan University of Technology and Business, Changsha 410205, China \\ 3 Key Laboratory of Petroleum Resource Research, Institute of Geology and Geophysics, \\ Chinese Academy of Sciences, Beijing 100029, China; nanqiaodu@mail.iggcas.ac.cn (N.D.); \\ xuyi@mails.iggcas.ac.cn (Y.X.) \\ 4 University of Chinese Academy of Sciences, Beijing 100049, China \\ 5 College of Geo-exploration Science and Technology, Jilin University, Changchun 130026, China; \\ gongbozhang@mail.iggcas.ac.cn \\ 6 Ministry of Land and Resources Key Laboratory of Applied Geophysics, Jilin University, \\ Changchun 130026, China \\ 7 State Key Laboratory of Geodesy and Earth's Dynamics, Innovation Academy for Precision \\ Measurement Science and Technology, Chinese Academy of Sciences, Wuhan 430071, China \\ * Correspondence: jiazhuo16@mails.jlu.edu.cn; Tel.: +86-133-3154-0160
}

Citation: Li, X.; Jia, Z.; Du, N.; Xu, Y.; Zhang, G. Structural Characteristics of Moho Surface Based on Time Series Function of Natural Earthquakes. Remote Sens. 2021, 13, 763. https:// doi.org $/ 10.3390 /$ rs 13040763

Academic Editor: Panagiotis Elias

Received: 18 December 2020

Accepted: 16 February 2021

Published: 19 February 2021

Publisher's Note: MDPI stays neutral with regard to jurisdictional claims in published maps and institutional affiliations.

Copyright: () 2021 by the authors. Licensee MDPI, Basel, Switzerland. This article is an open access article distributed under the terms and conditions of the Creative Commons Attribution (CC BY) license (https:// creativecommons.org/licenses/by/ $4.0 /)$
Abstract: Remote sensing is a non-contact, long-distance detection technology. The reflection characteristics of a seismic wave can be used to detect remote and non-contact targets. Based on the reflection characteristics of a seismic wave, the underground structure in Tengchong Volcanic Area is explored. In order to further study the deep structure and magmatic activity of the crust in the volcanic area, we carried out a one-year mobile seismic observation. In this paper, nine broadband seismic stations were set up in the Tengchong Volcanic Area, and 3350 receiver function waveforms were collected. The crustal thickness, average wave velocity ratio, and Poisson's ratio below these stations were calculated by the receiver function method, and the velocity structure near the Moho below these stations was evaluated. Combined with topographic data from SRTM3 (Shuttle Radar Topography Mission 3), this study reveals the dynamic relationship among crustal structure, crustal magmatism, and regional tectonic movement. Mantle upwelling plays an important role on the Moho uplift in the northern Tengchong Volcanic Area, and there are interconnected intracrustal magma chambers in the upper platform. The evaluation results of the Moho transition zone also indicate that the Dayingjiang fault is closely related to the tectonic activity of the Tengchong Volcanic fault.

Keywords: receiver function; Tengchong volcano; magmatic activity; Moho surface

\section{Introduction}

It is one of the main tasks of modern seismology to detect the Earth's internal structure with seismic wave data. In the past 10 years, the receiver function method for obtaining the structure of crustal and mantle discontinuities using teleseismic data recorded by broadband seismic arrays has developed rapidly and obtained a series of important results. Langston studied this problem as early as 1979, gave the source equivalent assumption, and separated the receiver function from the long period teleseismic body wave [1]. Owens et al. extended this method to broadband records and developed a linear inversion method of the receiver function to study the structure of the Kampalan Plateau in 1984 [2]. King et al. studied the crustal structure under the GDSN (Global Digital Seismic Network) station and summarized the receiver function method in 1995 [3]. In order to improve the resolution of mechanism imaging results, Yuan et al. (1997) developed the migration 
stack method of the receiver function and used it to study the lateral variation of the upper mantle discontinuity [4]. They have successfully studied the crust and upper mantle structure of the Qinghai Tibet Plateau and the Andes [5]. Liu has undertaken detailed research on the observation of broadband seismic arrays and the research of receiver function method, such as the nonlinear inversion of the receiver function and the method of synthesizing the receiver function of a teleseismic body wave in three-dimensional transversely inhomogeneous media [6-8]. Wu et al. developed the deconvolution method in the time domain and studied the crustal structure of the Qinghai Tibet Plateau with the receiver function [9]. Although the receiver function method was proposed as early as the 1970s, it is difficult to obtain the fine structure of the study area due to the scarcity of stations and the long-period data obtained by manual digitization at that time, and its advantages are not obvious compared with other methods [10-12]. In recent years, with the rapid development of digital observation technology and mobile station observation, the receiver function method has been widely used, the results of studying the structure of the crust and upper mantle beneath the seismic array emerge endlessly [13-15], and the receiver function has gradually become an effective means to study the structure of the crust and upper mantle.

After summarizing the successful work and characteristics of the receiver function, we carried out receiver function imaging in the Tengchong Volcano Area. Tengchong is one of the youngest volcanic areas in China and an important area of Cenozoic volcanism and magmatism. About 70 volcanoes of different sizes are distributed in the area centered on the Tengchong Basin [16]. Since the Pliocene, volcanic activities have gradually migrated from the periphery to the center of the Tengchong Basin. The latest volcanoes are mainly concentrated in the center of the Tengchong Basin, forming a north-south beaded volcanic chain, and there was magmatic activity in Holocene [17]. Most of the volcanic rocks are high-k calc alkaline basalt and andesite, and the formation reason is closely related to the heat flow activity caused by mantle upwelling [18]. In the recent 10 years, some geophysical explorations have been carried out in Tengchong area, including artificial seismic sounding, magnetotelluric sounding, and natural seismic tomography. These results reveal the geophysical characteristics of the Huoshan area [19]. Lou et al. and Wang et al. discovered the low velocity anomaly of the upper crust by analyzing the artificial seismic sounding data, analyzed the corresponding geothermal activity, and obtained the fault structure information in the areas mentioned above [20,21]. Zhao et al. calculated the relative geothermal gradient by using the hot spring data and found that there were three high heat flow areas in Tengchong Volcanic Area so as to analyze the distribution and activity of the magma chamber [22]. Xu et al. retrieved the 3D P-wave velocity structure of Tengchong and its adjacent areas using the data of the mobile seismic observation network, and analyzed the relationship between the low velocity anomaly and magmatic activity in the crust [23]. He et al. and Feng et al. used the receiver function method to analyze the S-wave velocity structure under the station [24,25]. Using magnetotelluric sounding data, Jiang et al. studied the electrical structure of volcanic groups in the area, and determined the depth and scale of the magma chamber in the crust [24].

At present, natural seismic sounding can only reflect the comprehensive effect of crustal magmatism and heat flow, and it is difficult to obtain high-resolution crustal structure information. The distribution of stations used in the receiver function study is relatively discrete, which makes it difficult to reflect the structural details of magmatic activity in volcanic areas. To solve these problems, we have carried out temporary earthquake observation for more than one year by laying 9 broadband seismographs. Based on the teleseismic receiver function, the high-resolution crustal structure of the volcanic area in northern Tengchong is obtained, and the influence of deep dynamic processes such as mantle upwelling on the crustal structure of the volcanic area is discussed.

The dynamic relationship between magmatism and regional tectonics is of great significance for understanding the characteristics of magmatism in volcanic areas and establishing the geological model of the magma chamber. In this paper, the crustal thickness 
and mean wave velocity / Poisson ratio under the stations are calculated by using the seismic data recorded by these stations. It is expected to provide more detailed information for the study of magmatic activities and deep dynamic processes in the Tengchong Volcanic Area.

In this study, we used topographic data from Shuttle Radar Topography Mission 3 (SRTM 3) which is measured by the National Aeronautics and Space Administration (NASA) and National Imagery and Mapping Agency (NIMA). The horizontal resolution of this radar data is 3 arc-seconds or $90 \mathrm{~m}$. In the discussion, we also demonstrated the utilization of remote sensing as complementary or auxiliary data to supporting our results. Finally, we have improved the discussion about magma and justify it in a more concise way by applying more data and a 3-D model.

\section{Materials and Methods}

\section{Receiver Function}

When a natural earthquake occurs, part of the seismic signal will be received by the broadband seismometers on the ground. The fastest signal to reach the broadband seismometers is the P-wave signal (the direct P-wave in Figure 1). The $\mathrm{P}_{\mathrm{S}}$ wave represents the fact that the $\mathrm{P}$ wave encounters the Moho in the process of propagation, and transforms into an $\mathrm{S}$ wave. In the same way, $\mathrm{P}_{\mathrm{P}} \mathrm{P}_{\mathrm{S}}$ and $\mathrm{P}_{\mathrm{S}} \mathrm{P}_{\mathrm{S}}+\mathrm{P}_{\mathrm{P}} \mathrm{S}_{\mathrm{S}}$ represent multiple conversions and are finally received as signals by the broadband seismometers [9], which can be shown in Figure 1.

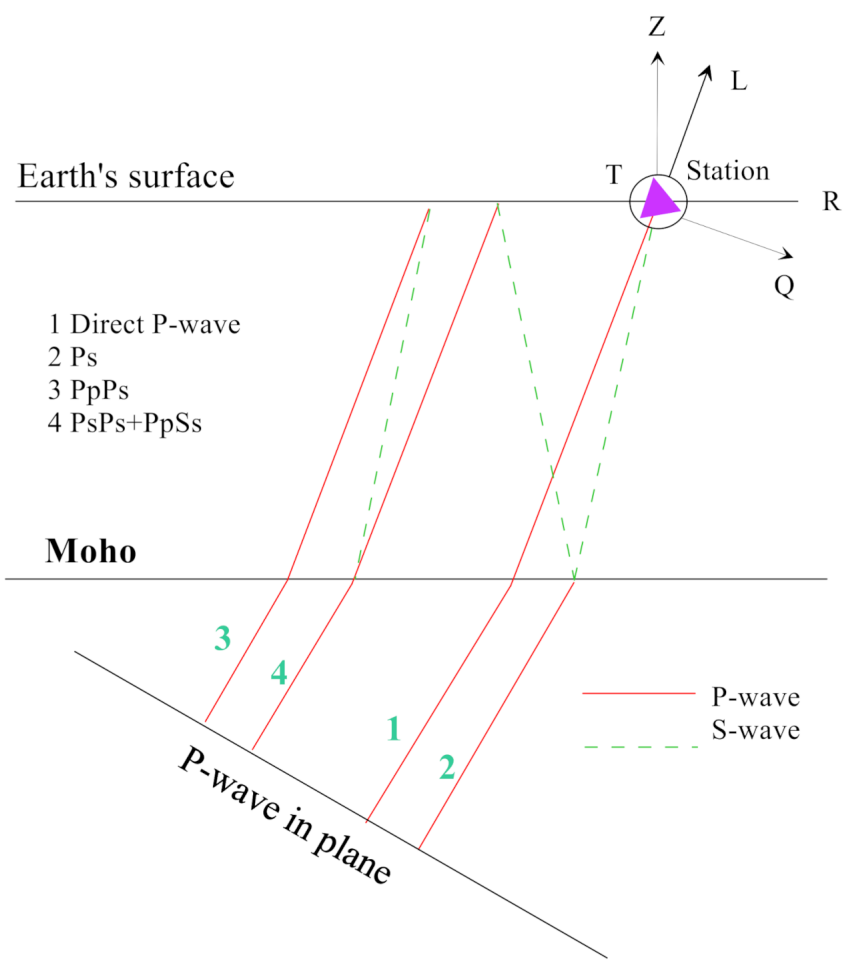

Figure 1. Ray path diagram of P-wave receiving function in single-layer homogeneous medium.

According to the characteristics and propagation path of the $\mathrm{P}$ wave and $\mathrm{S}$ wave, we can know the time order of the $\mathrm{P}$ wave, $\mathrm{P}_{\mathrm{S}}$ wave, $\mathrm{P}_{\mathrm{P}} \mathrm{Ps}$ and $\mathrm{P}_{\mathrm{S}} \mathrm{P}_{\mathrm{S}}+\mathrm{P}_{\mathrm{P}} \mathrm{S}_{\mathrm{S}}$ reaching the broadband seismometer on the surface, as shown in Figure 2. The PpPs wave represents the fact that the P-wave generated by the source after passing through the Moho surface is still a P-wave. After it continues to propagate and reaches the surface, it reflects back to the Moho surface. After reflection from the Moho surface, it is converted into an S-wave and finally received by the broadband seismometer on the surface. Compared with the direct $\mathrm{P}$ wave and Ps wave, PpPs wave propagation time is longer and the reception occurs later. 


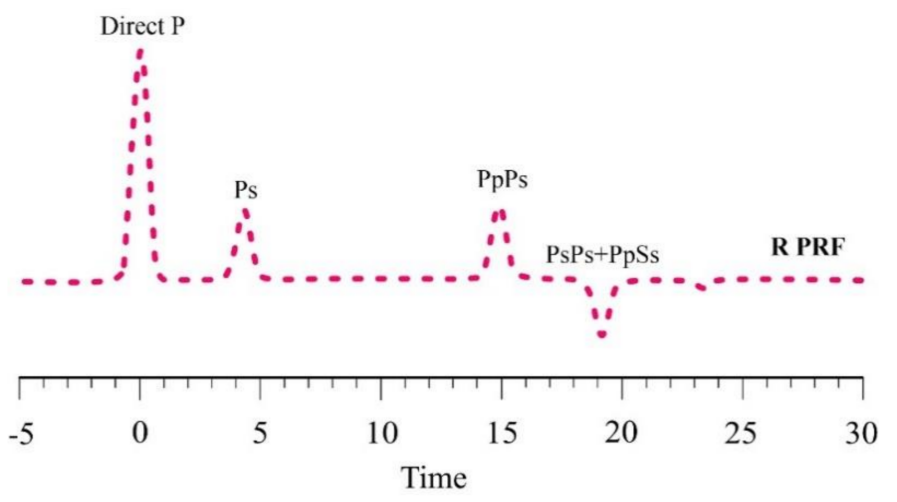

Figure 2. Waveform shape rules of receiver function.

$\mathrm{P}_{\mathrm{S}} \mathrm{P}_{\mathrm{S}}$ and $\mathrm{P}_{\mathrm{P}} \mathrm{S}_{\mathrm{S}}$ represent three transitions of the $\mathrm{P}$-wave during projection and reflection propagation. Therefore, according to several waveform propagation laws in Figure 1, a waveform sequence with obvious characteristics can be collected on the broadband seismometer on the surface. For each natural seismic event, each broadband seismometer will obtain a receive function similar to the time series with a pulse shape, as shown in Figure 2. The receiver function will carry a lot of velocity information about the undulation of the Moho surface and the underground structure. We can infer the fluctuation of the underground structure and the Moho surface according to the collected large number of receiver functions.

\section{Data}

The Earth's seismic events will occur from time to time, so through the long-term deployment of stations, a series of receiver function data will be collected. The receiver functions will carry a lot of information about the inner crust. We can rely on these receiver functions to study the region. Therefore, this paper chooses to set up stations in the Tengchong area. Combined with the geological background and conditions of this area and through the collected receiver function data, the geological structure and tectonic movement in this area are inferred and studied.

Tengchong is one of the youngest volcanic areas in China and an important area of Cenozoic volcanism and magmatism. About 70 volcanoes of different sizes are distributed in the area centered on the Tengchong Basin. Since the Pliocene, volcanic activities have gradually migrated from the periphery to the center of the Tengchong Basin. The latest volcanoes have been mainly concentrated in the center of the Tengchong Basin, forming a north-south beaded volcanic chain, including a volcanic lake, Heikong Mountain, Dakong Mountain, Daying Mountain, Laoguipo, Maan Mountain, etc., and magmatic activities occurred in the Holocene.

The seismic observation is located between Gudong and Heshun of Tengchong, passing through Laoguipo, Daying Mountain, Dakong Mountain, Heikong Mountain and the volcanic lake successively from south to north, with a length of about $40 \mathrm{~km}$ (Figure 3). A total of 9 broadband seismometers were installed along the survey line, with an average distance of about $4 \mathrm{~km}$. The SHZ, DYC, and MZT stations are located in Laoguipo, Daying Mountain and Big kong Mountain, respectively, and the HSH station is located in Huoshanhu.

Each station is equipped with a digital collector, seismic sensor, and GPS time service system. The sampling rate is $40 / \mathrm{s}$, and the continuous observation period is 14 months from May 2015 to July 2016. According to the earthquake catalog issued by United States Geological Survey (USGS), 241 teleseismic events with a magnitude above five, epicentral distance between $30^{\circ}$ and $90^{\circ}$, and clear phase were selected from the recorded data during this period. The epicentral distribution shows that most of the earthquakes are distributed in the Western Pacific region northeast and southeast of Tengchong, as shown in Figure 4. 


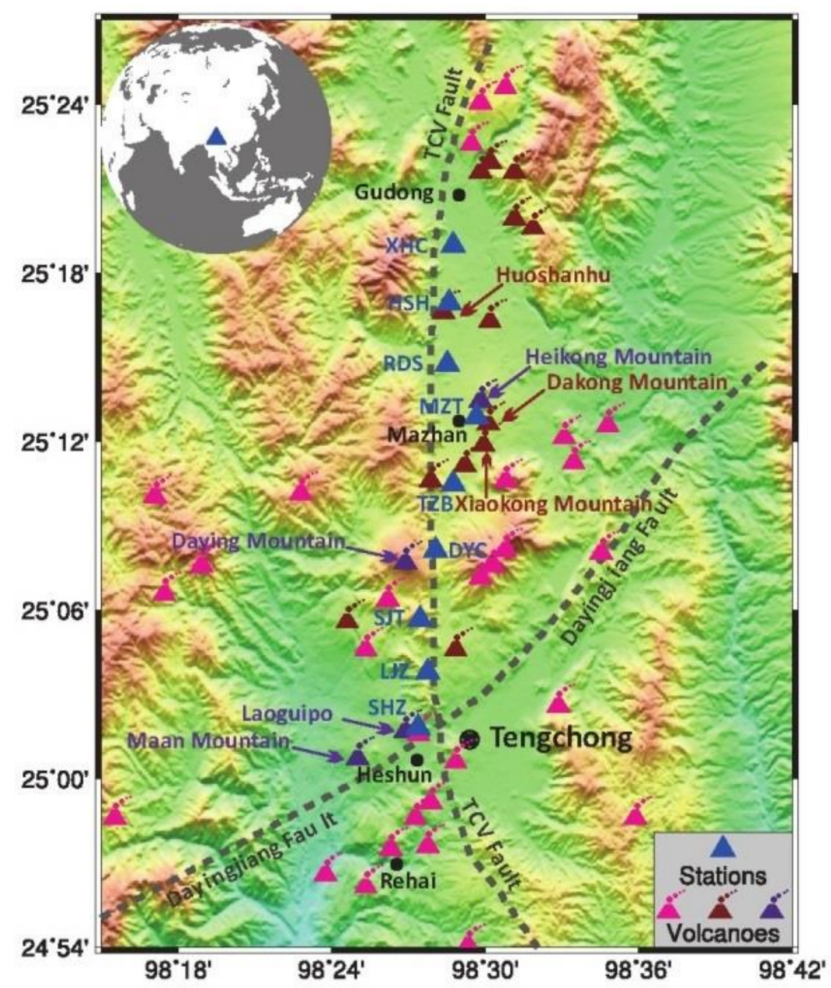

Figure 3. Geological background and distribution of temporary seismic stations in the Tengchong area.

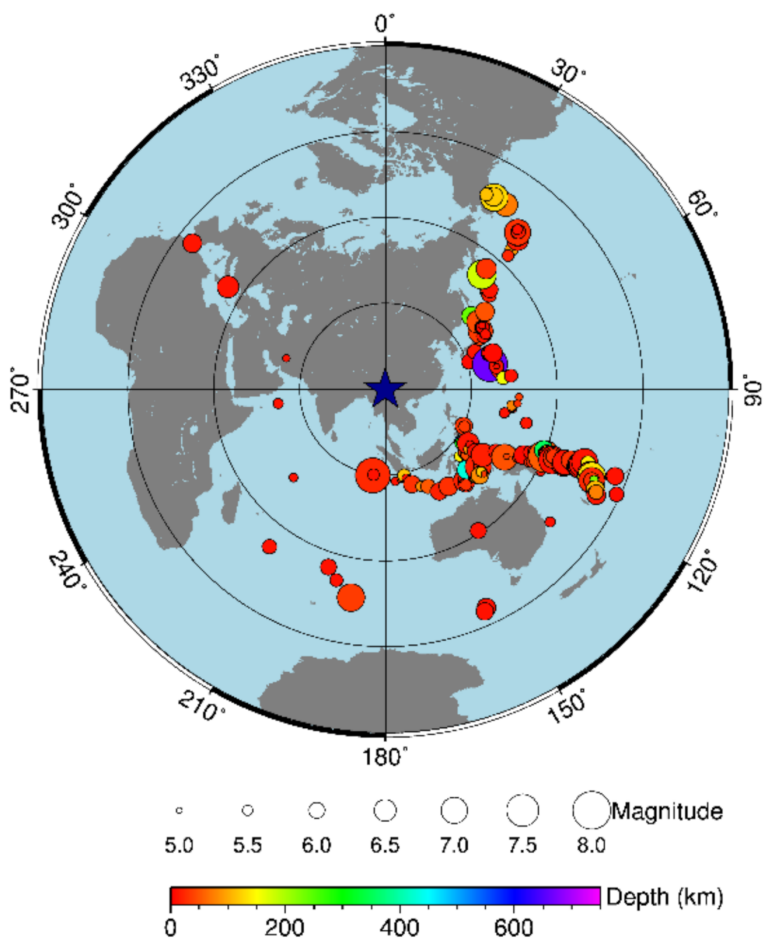

Figure 4. Epicenter locations of $\mathrm{Ms} \geq 5.0$ earthquakes.

Theoretically, we will obtain 3350 receiver functions, but there are many receiver functions that do not conform to the waveform rules. We need to delete these functions that do not conform to the rules, otherwise they will affect the information carried by the receiver functions with good quality. An example of these low-quality waveforms is shown in Figure 5. The main reason for this phenomenon is that the underground medium structure is too complex. Deleting them will improve the overall quality of the receiver 
function and reduce uncertainties. Compared with the waveform sequence in Figure 2, several waveforms in Figure 5 carry many inferior signals, which will cover useful signals. After we remove these poor receiver functions, we will obtain some relatively pure receiver functions. It is more conducive for using these functions to our judgment and analysis of underground structures.
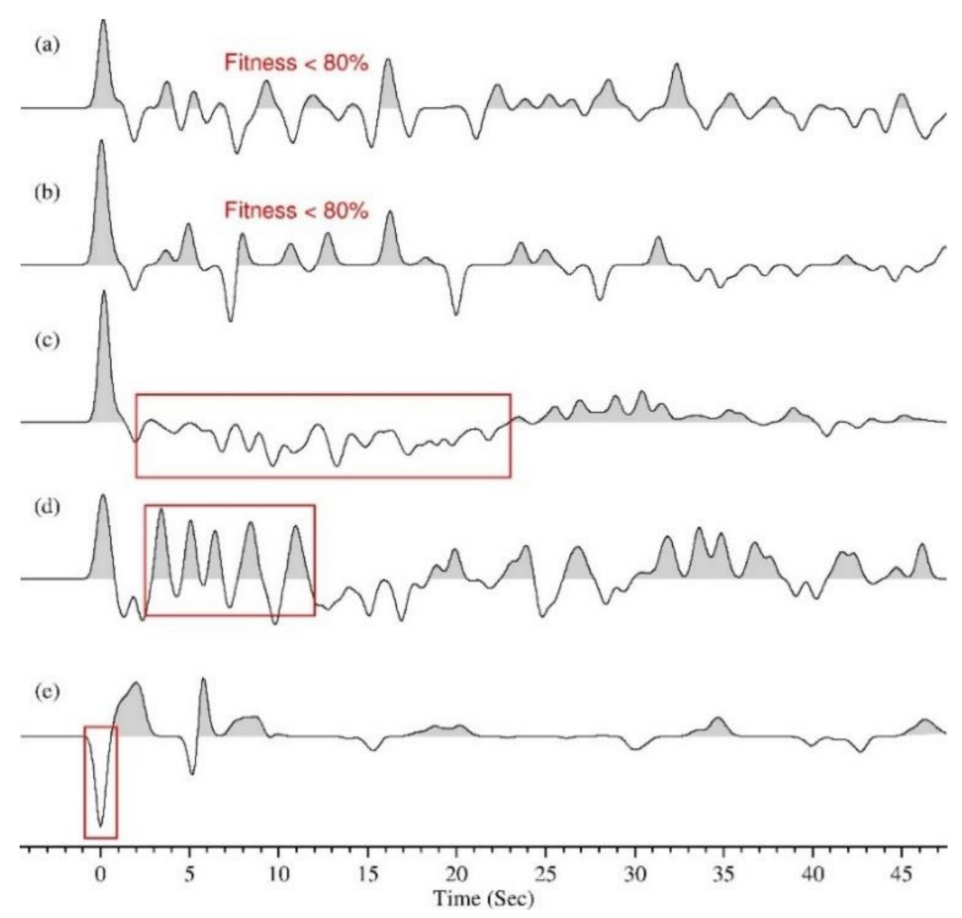

Figure 5. Poor-quality receiver function; (a) and (b) the cross-correlation between tangential component and convolution of receiving function with vertical component is less than $80 \%$; (c) the lack of $\mathrm{P}_{\mathrm{S}}, \mathrm{P}_{\mathrm{P}} \mathrm{P}_{\mathrm{S}}$ and $\mathrm{P}_{\mathrm{P}} \mathrm{S}_{\mathrm{S}}+\mathrm{P}_{\mathrm{S}} \mathrm{P}_{\mathrm{S}}$ phase; (d) transition phase is too strong; (e) direct $\mathrm{P}$-wave is minus.

When we delete all the receiver functions with poor quality, we obtain the receiver functions in Figure 6. This diagram shows all the high-quality receiver functions of MZT station. The figure on the left panel shows the earthquake occurred on the Earth during the period of the station layout and different colors represent the distance between the earthquake event and MZT station. The figure in the middle represents all the receiver functions with high quality received by the station after the earthquake. We select five receiver functions from all the receiver functions, as shown in the figure on the right panel. We can see the clear amplitudes of the direct $\mathrm{P}$-wave, $\mathrm{P}_{\mathrm{S}}$ wave, and $\mathrm{P}_{\mathrm{P}} \mathrm{P}_{\mathrm{S}}$ wave.
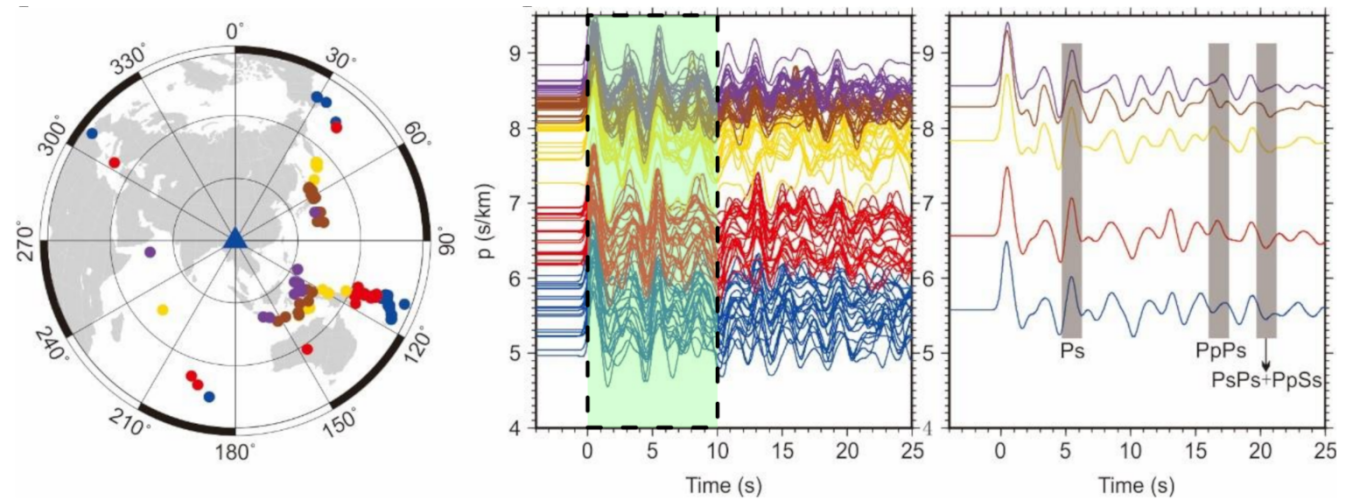

Figure 6. Stacking receiver function from the station MZT. 
We can see that there are many other signals in addition to $\mathrm{P}_{\mathrm{S}}, \mathrm{P}_{\mathrm{P}} \mathrm{P}_{\mathrm{S}}$ and $\mathrm{P}_{\mathrm{S}} \mathrm{P}_{\mathrm{S}}$ sequence from Figure 6. These signals sometimes mislead us to extract $P_{S}, P_{P} P S$ and $P_{S} P_{S}$ phases. Multi-frequency filtering would help us pick up specific amplitude signals. As shown in Figure 7, we intercept the waveform data of 0-10 s from Figure 6. At the same time, we filter the intercepted data with Gaussian coefficients of $(\alpha=1.0,2.0,3.0,4.0,5.0)$. Different Gaussian coefficients represent different frequencies. According to the receiver function under different frequencies, seismic wave information under MTZ station can be reflected. As shown in the Figure 7, the direct $\mathrm{P}$-wave is the blue peak near the time of $0 \mathrm{~s}$, and the $\mathrm{P}_{\mathrm{S}}$ wave is at the position of about $5 \mathrm{~s}$, and we use red arrows to mark the direct P-waves and $P_{S}$ waves.
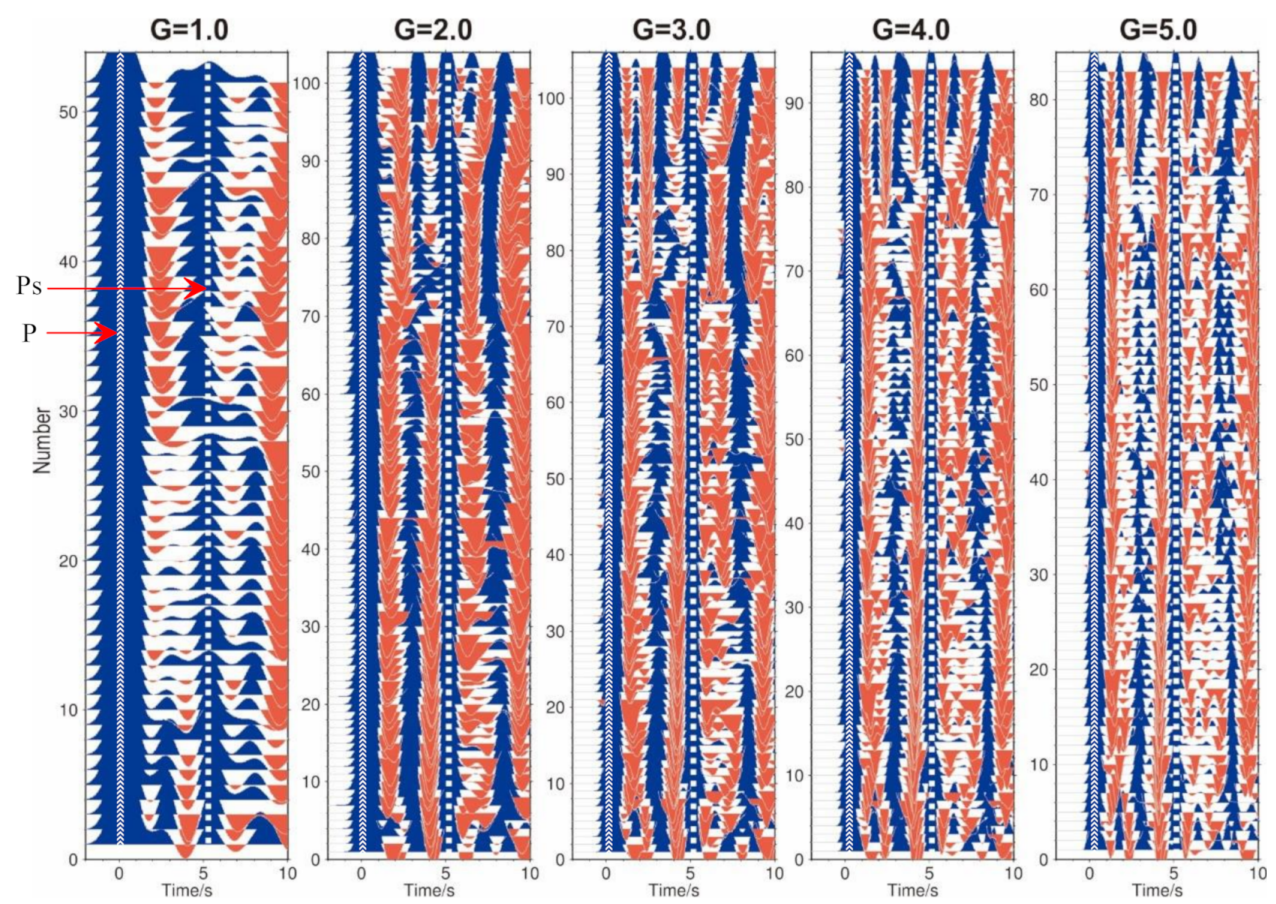

Figure 7. P-wave receiver functions from the station MZT.

When we change Gaussian factor from 1.0 to 5.0 at a 0.5 interval, we can still clearly distinguish the $\mathrm{P}$-wave and $\mathrm{P}_{\mathrm{S}}$ wave information. This effect is due to the fact that these two phases carry the structure information of the Moho discontinuity. When the Gaussian coefficient is low $(\alpha=1)$, the frequency is also very low. At the same time, this filter will automatically filter some signals with higher frequency, which may cause some effective signals unrecognized. On the contrary, if the Gaussian coefficient is too high, there will be too many high-frequency signals to achieve the purpose of filtering. For the above reasons, we consider using a Gaussian coefficient of $\alpha=2$ and it can be seen that the data imaging effect under this coefficient is general.

Figure 7 is the image of the MZT receiver function. We can see that the waveforms become sharper with the increasing Gaussian factor, and we can distinguish several waveform sequences from the figure. When $G=2$, the waveform sequence is relatively neat and the signal is clear. However, the receiving function received by MZT only represents the structure information under MZT. When we put the waveform sequences of 9 stations together, we can obtain the waveform signals of all stations and thus can obtain the lateral variation of structures beneath these 9 stations, as shown in Figure 8 (alpha $=2$ ). We can clearly see the waveform information of $\mathrm{P}_{\mathrm{S}}, \mathrm{P}_{\mathrm{P}} \mathrm{P}_{\mathrm{S}}$ and $\mathrm{P}_{\mathrm{P}} \mathrm{S}_{\mathrm{S}}+\mathrm{P}_{\mathrm{S}} \mathrm{P}_{\mathrm{S}}$ from the figure and we have made corresponding marks in the figure. The amplitude and time information of these signals are related to the thickness and depth of the Moho. According to these waveforms, we can further study the characteristics and properties of the Moho. 


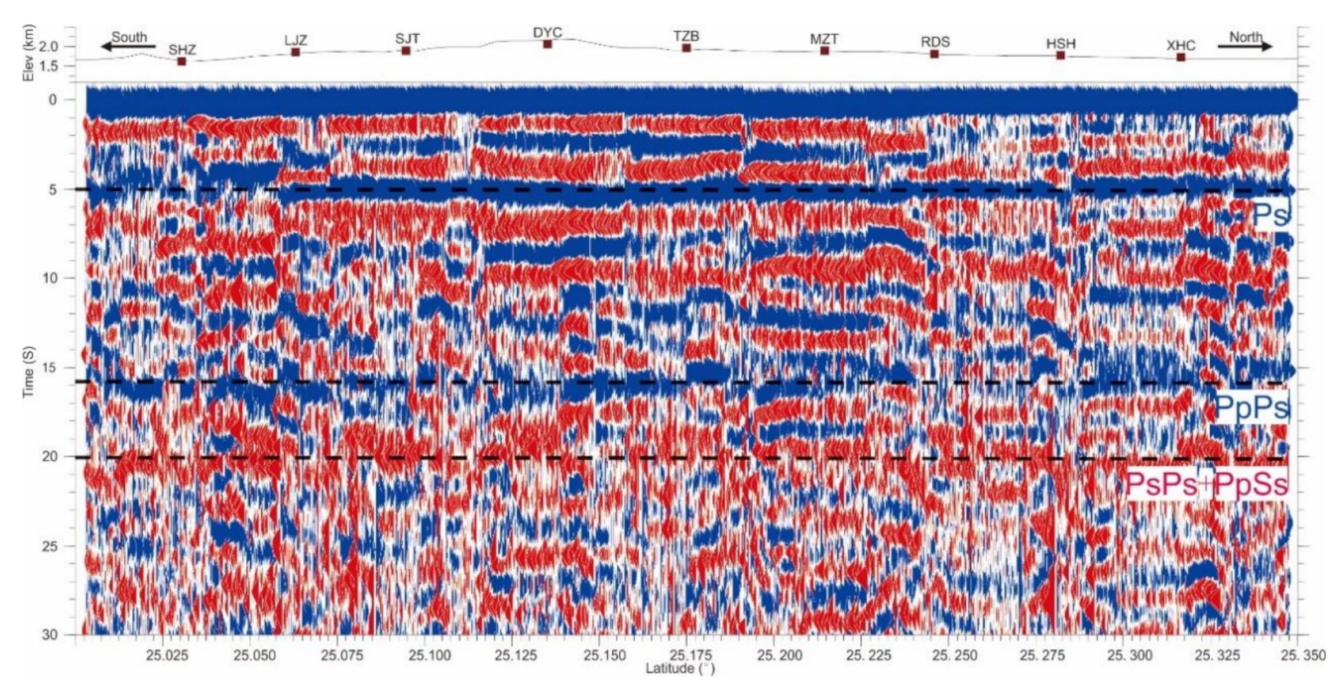

Figure 8. Receiver function for Gaussian factor 2.0 from 9 seismic stations along this profile line.

\section{Data-Processing Imaging}

\subsection{H-k Stack}

Since Zhu and Kanamori put forward the receiver function $H-k$ stack method, it has become a conventional tool to deal with the crustal structure [25]. The purpose of $H-k$ method is to extract crustal thickness parameters and P-wave velocity ratio parameters by receiver function. Poisson's ratio can reflect the changes of crustal rock composition and can be obtained by using wave velocity ratio. These two parameters are of great significance for understanding the crustal structure. Under ideal conditions, these parameters obtained by the $H-k$ method are consistent with the real crustal structure.

Once the receiving function information received by 9 stations in Tengchong area is obtained, we need to further process and image the crust information beneath these stations by using the data. The position, size, shape, frequency and other parameters of the receiver function waveform can reflect the underground structure. Using the $H-k$ stacking method to scan the received function, we can obtain the crustal thickness and wave velocity ratio information. $\mathrm{H}$ represents the thickness of the crust and $\mathrm{k}$ represents the wave velocity ratio.

The stacking results are displayed with $\mathrm{H}$ and $\mathrm{k}$ as the coordinate axes respectively. The coordinates corresponding to the most concentrated position of the energy cluster represent the thickness and wave velocity ratio data of the crust. At the same time, we use four $G(1.0,2.0,3.0,4.0)$ values to test and the results of MZT are shown in Figure 9. We can see that with the changing of the Gaussian factors, the crustal thickness and the wave velocity ratio remain stable. The crustal thickness is between $32 \mathrm{~km}$ and $32.4 \mathrm{~km}$ and the wave velocity ratio is between 1.95 and 1.97 . Therefore, these two parameters represent the actual characteristics of underground media and can be used for further analysis and interpretation.

Since we have obtained the ratio of crustal thickness to wave velocity, Poisson's ratio within the crust can be obtained according to Formula (1).

$$
\sigma=0.5\left[1-\left(k^{2}-1\right)^{-1}\right]
$$

Therefore, according to the formula (1) and $H-k$ transformation, we can calculate the crustal depth, wave velocity ratio and Poisson's ratio under the nine stations in Tengchong area, which can be shown in Table 1. 

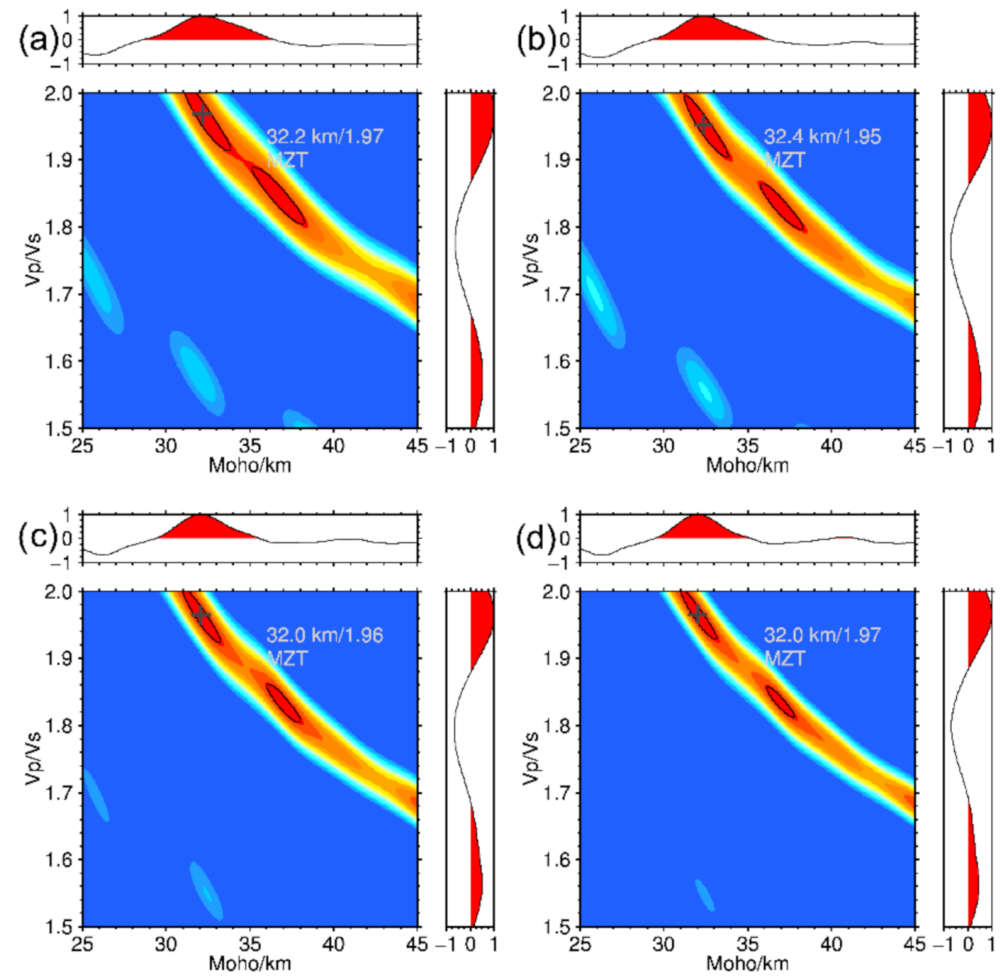

Figure 9. Results from stacking receiver functions of MZT. (a) Gauss factor 1.0 (b) Gauss factor 2.0 (c) Gauss factor 3.0 (d) Gauss factor 4.0

Table 1. Crustal thickness, $V_{p} / V_{s}$ ratio and Poisson's ratio.

\begin{tabular}{ccccccc}
\hline Number & Code & ${\text { Longitude } / \mathbf{E}^{\circ}}$ & Latitude/ & Moho/km & $V_{\boldsymbol{p}} / V_{\boldsymbol{s}}$ & $\boldsymbol{\sigma}$ \\
\hline 1 & XHC $^{\mathrm{a}}$ & 98.479 & 25.316 & 33.4 & 1.84 & 0.29 \\
2 & HSH $^{\mathrm{b}}$ & 98.476 & 25.282 & 33.7 & 1.82 & 0.28 \\
3 & RDS $^{\mathrm{c}}$ & 98.475 & 25.246 & 33.4 & 1.86 & 0.296 \\
4 & MZT $^{\mathrm{d}}$ & 98.494 & 25.214 & 32.4 & 1.95 & 0.31 \\
5 & TZB $^{\mathrm{e}}$ & 98.479 & 25.175 & 34.7 & 1.86 & 0.296 \\
6 & DYC $^{\mathrm{f}}$ & 98.468 & 25.135 & 35.6 & 1.84 & 0.29 \\
7 & SJT $^{\mathrm{g}}$ & 98.457 & 25.095 & 35.2 & 1.81 & 0.28 \\
8 & LJZ $^{\mathrm{h}}$ & 98.462 & 25.063 & 38.9 & 1.61 & 0.186 \\
9 & SHZ $^{\mathrm{i}}$ & 98.456 & 25.030 & 38.1 & 1.64 & 0.204 \\
\hline
\end{tabular}

a: Xinhecun; b: Huoshanhu; c: Randengsi; d: Mazhantai; e: Tangziba; f: Dayingcun; g: Shijiatian; h: Lujiazhai; i: Shangzhuangcun.

It can be seen from Table 1 that the crustal thickness and average wave velocity of stations at both ends of the survey line are consistent, while the calculation results of stations in the middle of the survey line are relatively discrete, which may be related to the magmatic activities under the volcanic area and the complex structure caused by mantlederived materials in the crust. In general, the average depth of the Moho is shallower in the north and deeper in the south, with local uplift or depression; the average wave velocity ratio and Poisson's ratio are also larger in the north of the profile, and more prominent at the MZT; with lower values in two stations at the south end.

\subsection{Common Conversion Point Stack}

Common conversion point $(\mathrm{CCP})$ stack in the receiver function is a widely used imaging technique for mantle velocity discontinuity. CCP stack imaging depends on $\mathrm{P}_{\mathrm{S}}$ conversion of the receiver function on the velocity interface. The depth information of the imaging results can be determined according to the time information received by the geophone. At the same time, in the area where the surface velocity changes greatly, the multiple reflection wave will also cause some influence on the CCP image. In this paper, 
the receiver functions collected in this paper will have a lot of conversion near the Moho surface, where the P-wave and S-wave transform from and to each other. According to the characteristics of the receiver function, $\mathrm{CCP}$ will display a strong Moho signal in the image after superposition, which can be seen in Figure 10.

(a)

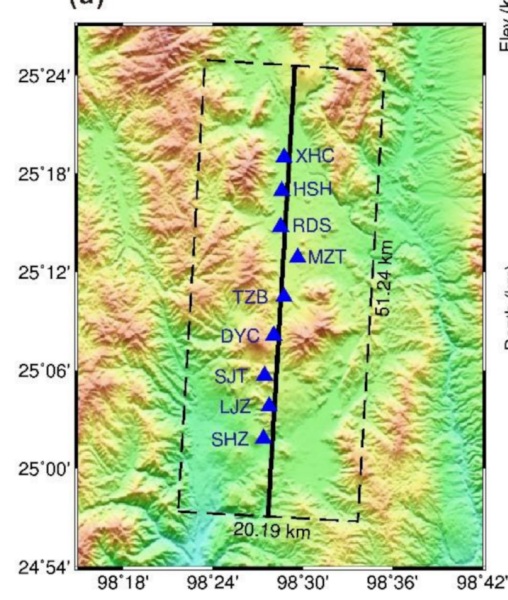

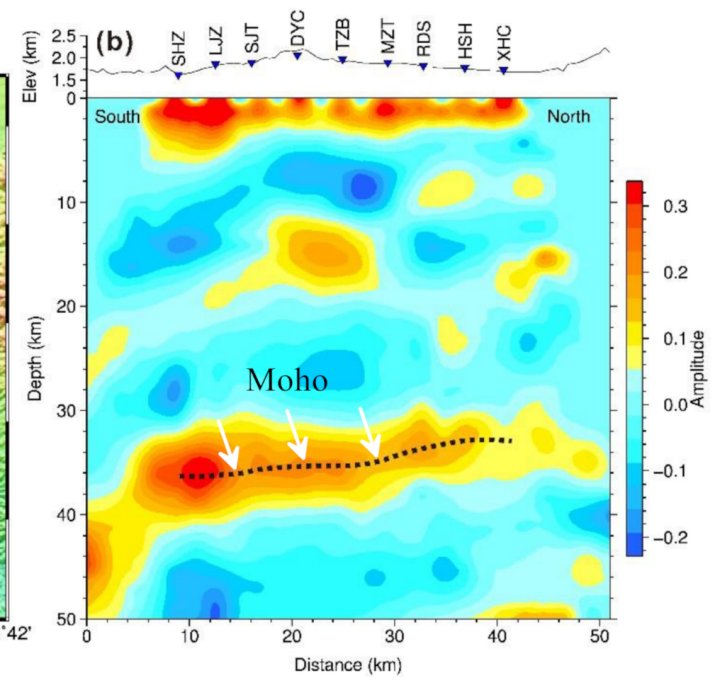

Figure 10. Common conversion point (CCP) stacking profile line.

From the results of CCP stack imaging, we can see the lateral change of Moho surface and the interface distribution in the shell. Except for some stations, the depth information of Moho surface is consistent with the $H-k$ stack result.

Therefore, through the test and verification of the two methods, it can be proved that the crustal thickness and wave velocity ratio calculated in this paper are very reliable. At the same time, further analysis and calculation can be carried out to infer the tectonic movement of underground media in the Tengchong Volcanic Area.

\subsection{Data Analysis}

The thickness of the transition zone of the Moho is of great geological significance. In order to further evaluate the velocity structure near the Moho discontinuity, Levin's method is used to evaluate the sharp degree of Moho surface under nine stations [26]. According to formula 2, we can calculate the thickness information of Moho transition zone by using the ratio of the frequency information and wave velocity of the receiving function:

$$
h=\frac{\lambda_{s}}{4}\left(\frac{\alpha}{\alpha-1}\right)=\frac{V_{s}}{1.92 G}\left(\frac{\alpha}{\alpha-1}\right)
$$

where $\alpha$ represents the ratio of P-wave velocity to S-wave velocity, $G$ is the Gaussian factor, and $\lambda_{S}$ represents the wavelength of the S-wave. According to the above formula, we can calculate the thickness of the Moho transition zone under the nine stations, as shown in Table 2.

Table 2. Results of evaluating Moho sharp.

\begin{tabular}{ccccc}
\hline Number & Code & Longitude $/ \mathbf{E}^{\circ}$ & Latitude/ $\mathbf{N}^{\circ}$ & $\Delta \mathbf{H} / \mathbf{k m}$ \\
\hline 1 & XHC & 98.479 & 25.316 & 0.8 \\
2 & HSH & 98.476 & 25.282 & 2.2 \\
3 & RDS & 98.475 & 25.246 & 0.9 \\
4 & MZT & 98.494 & 25.214 & 0.8 \\
5 & TZB & 98.479 & 25.175 & 0.9 \\
6 & DYC & 98.468 & 25.135 & 0.9 \\
7 & SJT & 98.457 & 25.095 & 0.9 \\
8 & LJZ & 98.462 & 25.063 & 3.7 \\
9 & SHZ & 98.456 & 25.030 & 3.5 \\
\hline
\end{tabular}


Our assessment results show that the Moho surface under the seven stations is quite sharp (the transition zone is less than $1 \mathrm{~km}$ ), but the thickness of the transition zone of HSH is more than $2 \mathrm{~km}$, and the thickness of transition zone of SHZ and LJZ is as high as $3.5 \mathrm{~km}$ and $3.7 \mathrm{~km}$. Combined with receiver function waveforms and regional geological data, the $\mathrm{HSH}$ station is located above the volcanic lake Volcanic Group, while the SHZ and LJZ stations are located at the intersection of the Dayingjiang fault and the Tengchong volcanic fault. The larger transition zone depth may imply complex double Moho structure, which is closely related to regional tectonic activity.

The receiver function $P_{S}$ seismic phase is about $5 \mathrm{~s}$, which is the blue pulse in the Figure 11. Blue pulses can be divided into three categories. The first category is not marked with an asterisk. Their $P_{S}$ phase is gradually sharper with the increase of Gaussian factor (frequency-dependent). For this kind of waveform, we directly take the highest Gaussian Factor to evaluate the thickness of the Moho transition zone. In the second category, the $\mathrm{P}_{\mathrm{S}}$ phase marked with a green asterisk does not change much with the increase of the Gaussian factor. We take the minimum Gaussian Factor evaluate the thickness of Moho transition zone. The third category is marked with red asterisk. With the increase of Gaussian factor, the waveforms of the $\mathrm{P}_{\mathrm{S}}$ phase become very complex, and many small wiggles appear. The changes of these waveforms usually correspond to the complex shape of the Moho. Under this circumstance, the thickness of the Moho transition zone could be estimated by the average value of each thickness obtained from the corresponding Gaussian factor.

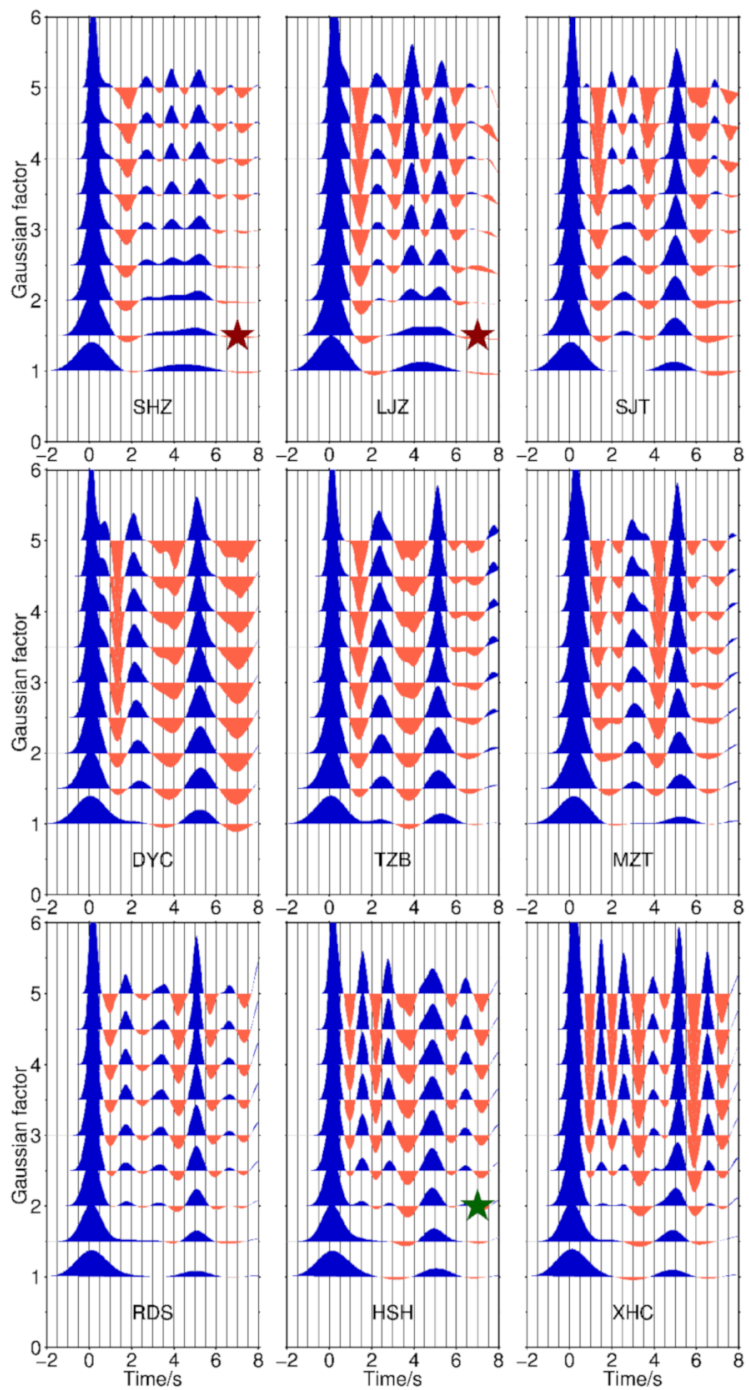

Figure 11. PS phase of receiver function with the changing of Gaussian factor. 


\section{Analysis}

\subsection{Crustal Thickness}

As shown in Table 1, the crustal thickness of the nine stations in the north of Tengchong is between $32.7 \mathrm{~km}$ and $38.9 \mathrm{~km}$. The crustal thickness of LJZ is the largest, and that of MZT is the smallest, with an average crustal thickness of $37 \mathrm{~km}$. Among them, the crustal thickness of the seven stations in the North varies slightly, with an average thickness of $36.1 \mathrm{~km}$, and the Moho surface near MZT is locally uplifted. The difference is between SHZ and LJZ at the southern end of the profile. The crustal thickness of these two stations is close to $38 \mathrm{~km}$, which is quite different from the seven stations in the north. According to the CCP results, the Moho depth gradually increases from north to south, which is consistent with the $H-k$ results. In the superimposed receiver function image, it can be seen that there is a large shift in the Moho converted phase at SHZ and LJZ stations, which should be the main reason for the change of crustal thickness under the two stations.

Results from previous research show that the Moho depth between Tengchong and Gudong is about $36-38 \mathrm{~km}$, and suddenly deepens nearly $40 \mathrm{~km}$ to the south near the Tengchong fault. The crustal thickness calculated by the SHZ and LJZ stations are close to Tengchong, and the calculated crustal thickness is roughly the same as the Moho depth of the artificial seismic sounding section. It is inferred that the increase of crustal thickness at these two stations may be related to the separation of the Tengchong fault. Because observation data from the station is more suitable to reflect the lateral change of crustal structure, it further confirms the control of the Tengchong fault on the crustal structure of volcanic area.

In the results of this paper, the smallest crustal thickness is located in the MZT of Da-Xiaokong Mountain, which are the areas with the strongest volcanic activity since the Holocene.

\subsection{Poisson's Ratio}

The average Poisson's ratio along the profile also has obvious changes. The Poisson's ratio under the seven stations in the north is $0.28-0.31$, with an average value of 0.29 , which is higher than the average value in the mainland, while the Poisson's ratio of SHZ and LJZ stations in the south is only 0.20 and 0.19 , which is obviously lower than that of other stations. The receiver function of regional stations shows that the average Poisson's ratio of the crust in the Tengchong area is mostly $0.26-0.32$ [27], which is close to the average Poisson compared with seven stations in the north of the profile.

\subsection{Dynamic Characteristics of Magmatism}

Crustal thickness and Poisson's ratio are very important for understanding the crustal structure and physical properties of the Tengchong Volcanic Area. Northern Tengchong is the most concentrated area of Holocene volcanoes. Although the current surface heat flow activity is relatively low and the distribution range of the geothermal anomaly area is small, magnetotelluric sounding has confirmed that there are intracrustal magma chamber in the area from Heikong Mountain to Da-Xiaokong Mountain [24].

According to the isotopic analysis of the gas escaping from the hot spring, the average temperature of the magma chamber reaches $524^{\circ} \mathrm{C}$ [22]. In addition, the volatile components of mantle-derived gases from hot springs, the rich mantle-derived mineral elements in volcanic rocks, and the low-velocity anomalies extending $100 \mathrm{~km}$ depth indicate that the magmatism in the volcanic area is related to the heat flow in the deep mantle. The study of Zhang shows that the crustal uplift and lithospheric thinning area in the Tengchong area is mainly located in the south of Tengchong County, and the crustal thickness change is not obvious in the volcanic area in the north of Tengchong, probably due to the relatively rare distribution of stations [28]. In this paper, the variation of crustal thickness and Poisson's ratio near the survey line is revealed by using the seismic observation data of dense point distance, and the corresponding relationship between the distribution of surface volcanoes and the activity of heat flow in the crust is shown. 
From Huoshanhu in the north to Daying Mountain in the south, the Moho depth in this area is obviously uplifted compared with the southern end of the survey line, and the average wave velocity ratio and Poisson's ratio are also relatively high, especially near MZT, where volcanoes are relatively concentrated, the uplift amplitude of the Moho is $1-2 \mathrm{~km}$ different from that of surrounding stations. This phenomenon indicates the relationship with the deep dynamic processes such as mantle upwelling beneath the volcanic area.

An experimental study shows that the mineral elements rich in ferromagnet tend to have higher Poisson's ratio, while the partial melting of rocks at high temperature can easily lead to the decrease of seismic wave velocity, especially the influence on S-wave velocity. Therefore, the regions with higher heat flow value also have higher wave velocity ratio. It can be seen that the medium is rich in mantle-derived minerals and the high heat flow in the magma chamber are the main reasons for the high crustal average velocity ratio and Poisson's ratio in the northern Tengchong Volcanic Area.

According to the analysis of Moho sharpness evaluation results, SHZ and LJZ stations are located near the intersection of the Dayingjiang fault and the Tengchong volcanic fault. As shown in Figure 12, the thickness of the transition zone more is than $3 \mathrm{~km}$ reveals the complex Moho structure. Since the Quaternary, the Dayingiiang fault has been characterized by left dip strike slip movement. During this period, Tengchong volcanic activity has been relatively intense, which indicates that the structural properties of the Moho have been modified by regional tectonic movement and magmatism. However, the thickness of the Moho transition zone at the HSH station above the volcanic lake is $2.2 \mathrm{~km}$, and the receiver function waveform does not show that it has a complex Moho structure. It indicates that the formation of the Moho transition zone is closely related to the upwelling of mantle-derived materials in the deep, suggesting that it may be a potential magmatic activity area. The average wave velocity ratio and Poisson's ratio under the HSH station are also relatively high, which is related to mantle upwelling and other deep-seated dynamic processes under the volcanic area.
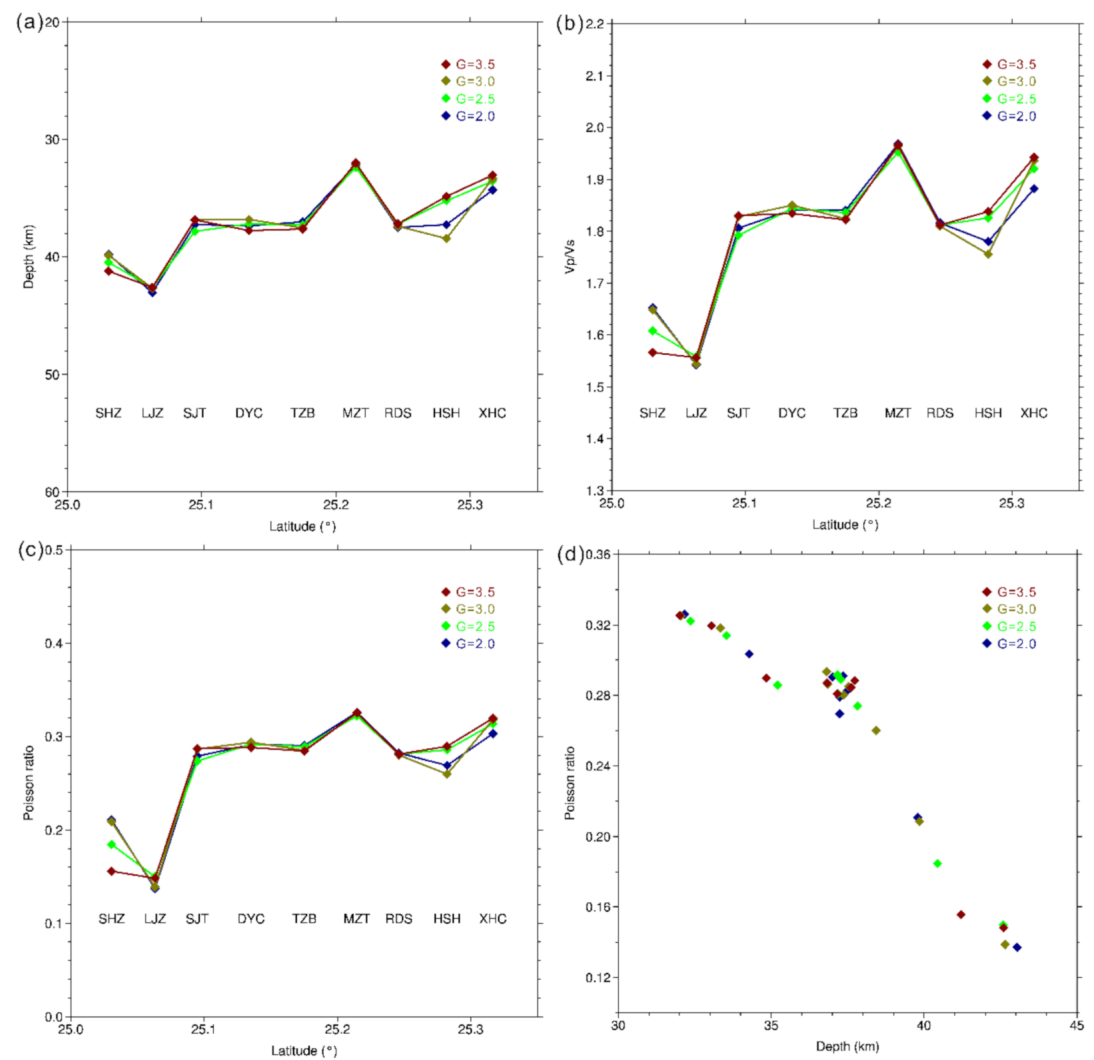

Figure 12. Comparison of $H-k$ stack results obtained from 9 stations using 4 frequency band receiver functions. (a) Moho depth; (b) $V_{p} / V_{s}$; (c) Poisson ratio; (d) Poisson's ratio data of depth. 
According to previous data, the relationship between crustal thickness and Poisson's ratio may imply important information about the formation and tectonic evolution of the continental crust. If the composition of the continental crust is single, that is, from the surface to the Moho, the Poisson's ratio of the crust will not be affected by the structural thickening or thinning. If the crustal composition is extremely heterogeneous in the horizontal direction, there will never be any simple relationship between the crustal thickness and Poisson's ratio. If the crust is composed of a series of horizontally extending layers of different lithology superimposed in the vertical direction, the strain is always preferentially concentrated in the weak rock layer rather than the strong rock layer in the process of structural compression shortening (thickening) or stretching extension (thinning). Under the same temperature and pressure, felsic rocks are more likely to form fold and nappe structures than basic rocks under the same temperature and pressure. As a result, the Poisson's ratio of the crust will decrease with the increase of the crustal thickness. According to the crustal thickness Poisson ratio curve (Figure 12d), the Poisson's ratio decreases with the increase of crustal thickness, which indicates that the overall evolution characteristics of the Tengchong Volcanic Area are controlled by magmatic activity and regional tectonic compression. The complex Moho structure under the LJZ and SHZ stations further confirms this conclusion.

Geochemical analysis shows that the volcanic rocks in the north of Tengchong are homologous magma, which may come from an interconnected magma chamber in the deep crust. Although the intracrustal magma chamber beneath Heikong Mountain have been confirmed by magnetotelluric sounding, as shown in Figure 13, the spatial distribution of magma chamber and their relationship with other volcanoes in the north-south direction are not clear because the profile passes through Heikong Mountain in the east-west direction. However, we further used topographic data from SRTM 3 which is measured by NASA and NIMA to explain the possible mechanism of magma activity. The horizontal resolution of this radar data is 3 arc-seconds or $90 \mathrm{~m}$. In the Figure 13, the elevation of tomographic map increases gradually while tomographic color changes from green to yellow. The distributions of volcanoes relate to the terrain with high elevation. According to the results, these regions have bigger transition zone and complex crust structure. Therefore, combined with topographic data and receiver function results, a possible dynamic model in Figure 13 is proposed to explain the mechanism of magma activity in the Tengchong Volcano Area.

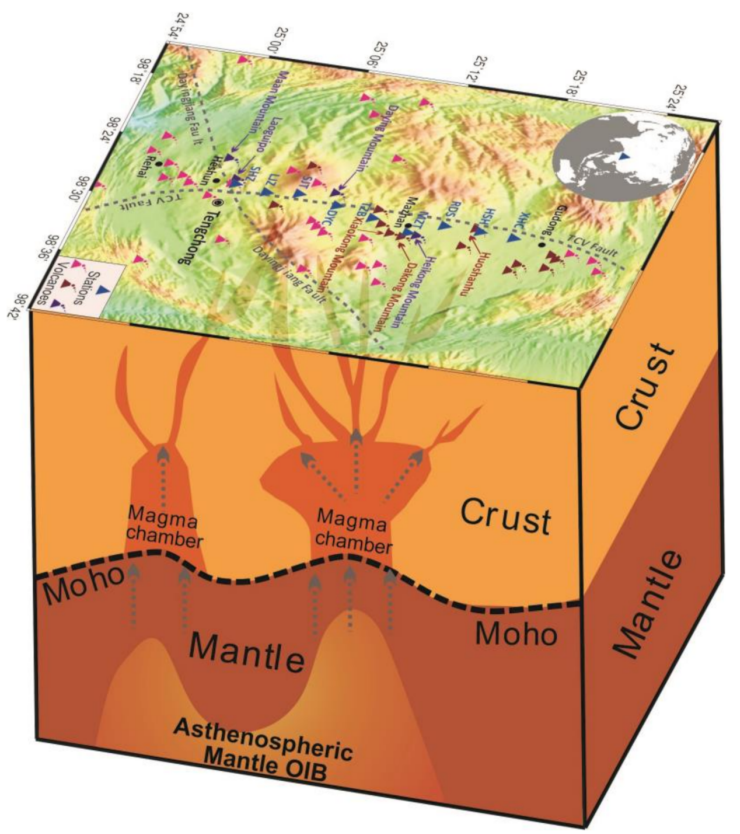

Figure 13. Schematic diagram of underground tectonic movement in the Tengchong area. 
According to the calculation results of this paper, the Moho uplift and high Poisson's ratio are mainly distributed in the area of about $20 \mathrm{~km}$ between volcanic lake and SJT, without further southward extension. This is quite consistent with the previous conclusions, indicating that the Heikong Mountain, Da-Xiaokong Mountain and Daying Mountain volcanoes in the north of Tengchong share an independent magma pocket, and they belong to two different magmatic storage systems with the geothermal anomaly near the southern hot sea.

\section{Conclusions}

We deployed dense mobile seismic profiles in the volcanic area of northern Tengchong, and calculated the crustal thickness, average wave velocity ratio and Poisson's ratio below the station by using the receiver function method. We also evaluated the velocity structure properties near the Moho below the station, and revealed the dynamic relationship between crustal structure, crustal magma activity, and regional tectonic movement.

The results show that the crustal thickness of the seven stations in the northern part of the survey line is $33.4-35.6 \mathrm{~km}$, the average wave velocity ratio is $1.82-1.92$, and the Poisson's ratio is $0.28-0.31$. The Moho uplift amplitude near Ma station is larger, which is 1-2 km different from the Moho depth of adjacent stations, and the average wave velocity ratio and Poisson's ratio also reach the maximum. The above phenomena indicates that the crustal structure in the volcanic area is affected by the mantle upwelling, which leads to the local uplift of the Moho. The heat flow activity in the crust and the residual high-density mantle source material are the main reasons for the high average wave velocity ratio and Poisson's ratio.

The Moho surface beneath the station near Hotsea in the south of the survey line has complex structural properties, and the thickness of its transition zone is more than $3 \mathrm{~km}$. This shows that it is closely related to the tectonic activities of the nearby Dayingiiang fault and Tengchong volcanic fault. In addition, according to the crustal thickness Poisson's ratio curve, it can be seen clearly that the Poisson's ratio decreases with the increase of the crustal thickness, which indicates that the overall evolution characteristics of the Tengchong Volcanic Area can be explained by delamination, that is, the upwelling of deep mantle-derived materials eliminates basic rocks in the crust, which leads to the decrease of Poisson's ratio in the crust.

Combined with the related data, it can be inferred that there is an interconnected intracrustal magma chamber beneath Tuan Mountain, Heikong Mountain, Da-Xiaokong Mountain and Daying Mountain in the north of Tengchong. The magma pocket has a range of about $20 \mathrm{~km}$ in the north-south direction. It is different from the geothermal anomaly near the Hotsea area and belongs to two different intracrustal magma storage systems. The evaluation depths of the Moho transition zone also show that the deep structure near the volcanic lake in the north is mainly restricted by magmatic activities, while in the south near the hot sea, it is affected by both magmatism and tectonic movement.

Author Contributions: X.L. contributed to the conception of the study; Z.J. performed the experiment; N.D. contributed significantly to analysis and manuscript preparation; Y.X. performed the data analyses and wrote the manuscript; G.Z. helped perform the analysis with constructive discussions. All authors have read and agreed to the published version of the manuscript.

Funding: This study was supported by the Natural Science Foundation of China (Grant 41374066).

Acknowledgments: This research was supported by the National Natural Science Foundation of China under Grant (41374066).

Conflicts of Interest: The authors declare no conflict of interest. 


\section{References}

1. Langston, C.A. Structure under Mount Rainier, Washington, Inferred from Teleseismic Body Waves. J. Geophys. Res. 1979, 84, 4749-4762. [CrossRef]

2. Owens, T.J.; Zandt, G.; Taylor, S.R. Seismic Evidence for an Ancient Rift beneath the Cumberland Plateau, Tennessee-A Detailed Analysis of Broad-Band Teleseismic P-Waveforms. J. Geophys. Res. 1984, 89, 7783-7795. [CrossRef]

3. Kind, R.; Kosarev, G.L.; Petersen, N.V. Receiver functions at the stations of the German Regional Seismic Network (GRSN). Geophys. J. Int. 1995, 121, 191-202. [CrossRef]

4. Yuan, X.; Ni, J.; Kind, R. Lithospheric and upper mantle structure of southern Tibet from a seismological passive source experiment. J. Geophys. Res. Solid Earth 1997, 102, 27491-27500. [CrossRef]

5. Huanjiu, X.I.; Youfeng, W.; Hailong, Z. Comparative Study of the Height, Weight and Chest Circumference of Children and Adolescents Between the Tibetan Plateau and the Andes. Acta Anthropol. Sin. 2014, 33, 198-213.

6. Liu, Z.; Niu, F.; Chen, Y.J. Receiver function images of the mantle transition zone beneath NE China: New constraints on intraplate volcanism, deep subduction and their potential link. Earth Planet. Sci. Lett. 2015, 412, 101-111. [CrossRef]

7. He, C.S.; Wang, C.Y.; Wu, J.P. S-wave velocity structure inferred from receiver function inversion in Tengchong volcanic area. Acta Seismol. Sin. 2004, 26, 11-18. (In Chinese)

8. Feng, J.; Fu, Z.W.; Gao, M.T. S wave velocity structure in Tengchong area inversed by receiver functions. Prog. Geophys. 2012, 27, 1328-1336, (In Chinese with English abstract).

9. $\mathrm{Wu}$, Q.J.; Zeng, R.S. The crustal structure of Qinghai-Xizang plateau inferred from broadband teleseismic waveform. Chin. J. Geophys. 1998, 41, 669-679.

10. Ammon, C.J.; Randall, G.E.; Zandt, G. On the nonuniqueness of receiver function inversions. J. Geophys. Res. Solid Earth 1990, 95, 15303-15318. [CrossRef]

11. Park, B.J.; Levin, V. Receiver Functions from Multiple-Taper Spectral Correlation Estimates. Bull. Seismol. Soc. Am. 2000, 90, 1507-1520. [CrossRef]

12. Juli, J.; Ammon, C.J.; Herrmann, R.B. Joint inversion of receiver function and surface wave dispersion observations. Geophys. J. R. Astron. Soc. 2010, 143, 99-112. [CrossRef]

13. Véronique, F.; Vinnik, L. Upper mantle stratification by P and S receiver functions. Geophys. J. R. Astron. Soc. 2010, 141, 699-712.

14. Shibutani, T.; Sambridge, M.; Kennett, B. Genetic algorithm inversion for receiver functions with application to crust and uppermost mantle structure beneath Eastern Australia. Geophys. Res. Lett. 2013, 23, 1829-1832. [CrossRef]

15. Jiang, C.S. Distribution characteristics of Tengchong volcano in the Cenozoic Era. J. Seismol. Res. 1998, 21, 309-319. (In Chinese)

16. Wang, Y.; Zhang, X.M.; Jiang, C.S. Tectonic controls on the late Miocene-Holocene volcanic eruptions of the Tengchong volcanic field along the southeastern margin of the Tibetan plateau. J. Asian Earth Sci. 2007, 30, 375-389. [CrossRef]

17. Chen, F.; Satir, M.; Ji, L. Nd-Sr-Pb isotopes of Tengchong Cenozoic volcanic rocks from western Yunnan, China: Evidence for an enriched-mantle source. J. Asian Earth Sci. 2002, 21, 39-45. [CrossRef]

18. Li, X.; Liu, J.Q. A study on the geochemical characteristics and petrogenesis of Holocene volcanic rocks in the Tengchong volcanic eruption field, Yunnan Province, SW China. Acta Petrol. Sin. 2012, 28, 1507-1516. (In Chinese)

19. Bai, D.H.; Meju, M.A.; Liao, Z.J. Magnetotelluric images of deep crustal structure of the Rehai geothermal field near Tengchong, Southern China. Geophys. J. Int. 2001, 147, 677-687. [CrossRef]

20. Lou, H.; Wang, C.Y.; Huang, F.G. Three-dimensional seismic velocity tomography of the upper crust in Tengchong volcanic area, Yunnan province. Acta Seismol. Sin. 2002, 24, 243-251. (In Chinese)

21. Wang, C.Y.; Huangfu, G. Crustal structure in Tengchong Volcano-Geothermal Area, western Yunnan China. Tectonophysics 2004, 380, 69-87. [CrossRef]

22. Zhao, C.P.; Ran, H.; Chen, K.H. Present-day magma chambers in Tengchong volcano area inferred from relative geothermal gradient. Acta Petrlog. Sin. 2006, 22, 1517-1528. (In Chinese)

23. Xu, Y.; Yang, X.T.; Li, Z.W. Seismic structure of the Tengchong volcanic area southwest China from local earthquake tomography. J. Volcanol. Geotherm. Res. 2012, 239, 83-91. [CrossRef]

24. Jiang, M.; Tan, H.D.; Zhang, L.W. Geophysical mode of Mazhan-Gudong magma chamber in Tengchong volcano-tectonic area. Acta Geosci. Sin. 2012, 33, 731-739. (In Chinese)

25. Zhu, L.P.; Kanamori, H. Moho depth variation in southern California from teleseismic receiver functions. J. Geophys. Res. 2000, 105, 2969-2980. [CrossRef]

26. Levin, V.; VanTongeren, J.A.; Servali, A. How sharp is the sharp Archean Moho? Example from eastern Superior Province. Geophys. Res. Lett. 2016, 43, 1928-1933. [CrossRef]

27. Li, Y.H.; Wu, Q.J.; Zhang, R.Q. The crust and upper mantle structure beneath Yunnan from joint inversion of receiver functions and Rayleigh wave dispersion data. Phys. Earth Planet. Inter. 2008, 170, 134-146. [CrossRef]

28. Zhang, L.; Hu, Y.L.; Qin, M. Study on crustal and lithosphere thickness of the Tengchong volcanic area in Yunnan. Chin. J. Geophys. 2015, 58, 1622-1633. 